high, by slides of the same material, surrounded by outer casing, also of the same, about 6 in. larger at the sides and back, covered with a jacket of felt and wood about 2 in. thick combined, to prevent conduction of heat. This outer space is for the reception of a mixture of salt and broken ice. The top should be closed by a lid, hinged in order to put in fresh ice and salt, and a tap should be made at the bottom to let out the meltings. There should be a door of iron covered with felt and wood, but it would not require any double casing for ice. The top would be as the door. Such a case to hold six bodies would occupy a space of about $7 \mathrm{ft} .9 \mathrm{in}$. long, $5 \mathrm{ft}$. 4 in. wide, and $6 \mathrm{ft} .2 \mathrm{in}$. high. Ice cases to hold a single body could be constructed on the same principle. When a body was required for examination or for any other purpose, a table capable of elevation could be placed before the open door and the shelf run out upon it. In many positions where steam or gas power could be used an ice-making machine could be employed instead of ice. It would be easy to make arrangements at the door end of the shelves, so as to give absolute security against any interference with the bodies within.

Cold, it appears to me, offers better advantages over other methods of preservation, leaving as it does the body completely intact. But by whatever means conservation may be effected its advantages are at once recognised as embracing the following points.

1. The prevention of disagreeable or dangerous odours. This is especially necessary where the mortuary is situated near houses or in hospitals; an instance of this latter has come under my notice where the mortuary is placed in the basement of the wards. In summer the effluvium finds its way into the windows of the wards; consequently, when an inquest is to be held urgent messages are sent to get the inquiry over directly, which is often impossible.

2 . The coroner's inquest need not be unduly hurried, and this is of much importance in populous districts, both from the many engagements of the coroner, but also that it enables the jurymen to receive fair notice, so that they may arrange their own business accordingly, and gives time for the collection of evidence, thus preventing the necessity of adjournments.

3. In regard to identification, it gives greater and more complete facilities for the recognising of the dead. It will be at once seen how important this is from a legal and social point of view. Hitherto a week only is possible for identifying a dead body, and not unfrequently only a day or two. But by the plan suggested there would be no limit of time; and I see no reason why, in cases where the body has not been identified at the time of inquest, it might not be removed from the local to a central mortuary, and thus preserved for a period-say, a year. Portions of bodies like those lately found may in like manner be placed and kept antil all means of inquiry concerning them should be exhausted, or may not the body of one dying far from his friends be preserved until arrangements can be made for burial or for a last look?

$$
\text { I am, Sir, yours truly, }
$$

$$
\text { A. Braxton HICKS, }
$$

January, 1885. Barrister-at-Law and Deputy-Coroner for Westminster and Surrey.

\section{THE M.D. EXAMINATION AT LONDON UNIVERSITY.}

To the Editor of THE LANCET.

SIR,-We have read with surprise and a certain degree of amusement the views of your correspondent who signs himself "M.B.," relating to the " undignified complaint of one who aspires to a good degree." He evidently regards the passing of examinations as a much higher test of a man's capabilities as a practical physician than do we, who must confess a certain leaning towards the "schoolboy view" of your former correspondent. Moreover, "M.B." probably possesses a greater faculty for remembering the various facts and minutiæ which are necessary to ensure success in an examination like that for the London degree than is possessed by the majority. On these grounds we can respect his riews. But when your anonymous correspondent turns aside and begins casting a slur on the teachers of practical medicine at the various London hospitals, contending "that he can count these teachers of clinical medicine on the fingers of one hand," we must confess to taking exception at his statement. The most obvious deduction that can be drawn from this remark is that either "M.B." has been endowed with an exceptional number of fingers, or that he has been singularly unfortunate in his experience. As we form two out of the remaining five who had the misfortune to be rejected in logic and psychology, though passing in medicine, we think that a disclaimer is not uncalled for.

We are, Sir, yours faithfully,

WALTER HUII.

St. Thomas's Hospital, January, 1885 . F. Foond CAIGER.

\section{THE CASE OF DR. BRADLEY.}

To the Editor of THE LANCET.

SrR,--In last week's issue I am said to have given it as my opinion that an epileptic fit would not be recovered from in less than half an hour. That such a statement was made by me either in or out of Court I most emphatically deny. On the Sunday following the alleged offence I had an interview with Dr. Bradley. I asked him what kind of a fit it was that Mrs. Swetmore had, as her mother and friends had told me that her attacks usually lasted upwards of half an hour. He said it was a fainting fit. On this point I should almost feel disposed to differ from him; for if, as he alleges, she had a fit, it would probably be one of an epileptoid character. The learned counsel for the defence did not dwell upon the probabilities of women of a neurotic taint (of which Mrs. Swetmore is a type) suffering from delusions. In fact, I do not remember being asked a single question on this very important subject. That Dr. Bradley did not take my advice and obtain a professional expert as a witness is equally as much regretted by me as yourself; but that he had an "independent witness," and one who sympathised with him in his terrible calamity, you may rest assured. I am, Sir, yours truly,

Ambrose M. Palmer, M.R.C.S., \&c. Whittington, Jan. 27th, 1885.

\section{LIVERPOOL.}

(From our own Correspondent.)

HOSPITAL SUNDAY AND SATURDAY.

Trre amount collected on Hospital Sunday has, as was feared, fallen short of previous years, owing to the inclement weather which prevailed, and also to the great depression of trade. It is hoped, however, that the deficiency may be made up by the improvement in the Hospital Saturday Fund, strenuous efforts being made to make this more generally known among working men, and to ensure more generous support. At the various annual meetings of the different medical charities which are now being held, the support received from Hospital Sunday is warmly acknowledged, and indeed is regarded as indispensable.

\section{THE HOSPITAL FOR WOMEN.}

The annual meeting of the Hospital for Women was held on the 26th inst., when the medical report read by Dr. Burton showed that the patients came not only from the city and neighbourdood, but from all parts of Lancashire, from Cheshire, North Wales, the Isle of Man, and elsewhere. The following was given as the summary of the year's work:The number of patients treated at the dispensary department was 3397 , with an attendance of 14,375 . The in-patients numbered 363 , with a mortality of 18 , which is small considering the dangerous nature of many of the cases and that there were 249 operations. The expenditure was $£ 1800$, all of which had been raised, the hospital thus paying its way. $£ 108$ was received from fifty paying patients, while the dispensary patients' contributions amounted to $£ 262$.

\section{THE INFIRMARY FOR CHILDREN,}

At the annual meeting of the Infirmary for Children it was reported that the in-patients numbered 998 during the year 1884, while the out-patients were 12,234 , and the daily attendances $30,7 \% 9$. In consequence of the depression of trade there was a deficiency of $£ 323$ on the income of the institution, which to that extent fell short of the expenditure. The following statistics respecting the mortality of children in this city was furnished to the committee by the medical officer of health:-Number of deaths under one 